\title{
Experiencing the Sense of Presence within an Educational Desktop Virtual Reality
}

\section{Borbála Berki}

Széchenyi István University, Doctoral School of Multidisciplinary Engineering Sciences; Egyetem tér 1, H-9026 Győr, Hungary

berki.borbala@sze.hu

Abstract: This study examines the sense of presence in MaxWhere desktop virtual reality. Thirty-one people participated in the research. The participants spend about fifteen minutes in the virtual environment. For measuring presence, the Igroup Presence Questionnaire (IPQ) was used. The results showed that more automatic navigation positively relates to spatial presence. This research also measured the participants' level of experience with the VR software. A significant difference was found in the spatial presence and experienced realism: the more experienced users gave higher ratings on both subscales. At the same time, the involvement and the general presence scores were similar in the two groups, which is advantageous in education as the presence is positively related to the learning outcome.

Keywords: desktop VR; presence; MaxWhere; virtual reality

\section{Introduction}

Digital transformation in education aims to arise the interest and engagement of students and help them in their learning experience. Cognitive infocommunications join forces of different research areas in order to reach an effective interaction between humans and computers and take full advantage of human cognitive capabilities with the help of infocommunication devices [1, 2].

There are several trends in digital transformation in education, such as gamification, personalized learning, augmented and virtual realities (VR). The latter can be present in education as virtual lecturing [3], virtual training [4, 5], field trips in special areas or museums [6]. VR is also getting attention in the industry [7] thus it is to introduce the virtual reality in the education of engineers such as different simulations in virtual laboratories $[8,9,10]$. Virtual reality can engage and motivate the students to acquire knowledge [11]. Moreover, it provides visualizations and interactions that are impossible or too expensive to 
perform in a real environment. According to a meta-analysis, virtual reality-based instruction is highly effective in K-12 and higher education [12].

Virtual reality means a three-dimensional, simulated environment that can be realized through different software and hardware. Virtual realities can be classified as full-immersive and non-immersive virtual realities. Full-immersive VR provides a high degree of interactivity, special input devices and a $360^{\circ}$ view with the help of a CAVE system or a head-mounted device (HMD). These special and expensive devices are rarely available in an ordinary educational institute. Therefore, the non-immersive or desktop virtual realities are more popular in the field of education as there is no need for special equipment only a computer and maybe a classic control device (mouse). These virtual realities show the simulated environment on a 2D display.

This paper is structured as follows. Section 2 shows the presence phenomenon and the process of immersion. Section 3 provides an overview of virtual realities in education and its relationship with the sense of presence. Section 4 presents the aim of the study and Section 5 shows the methods of this research such as the subjects, the measured variables, and the process. Section 6 presents the result of this study and Section 7 is a further discussion of these results. Finally, the results are briefly summarized in the Conclusion section.

\section{Presence}

Presence is a state of consciousness, a psychological phenomenon, the sense of "being inside" the virtual environment [13]. Despite their name, the nonimmersive virtual realities can also provide a sense of presence to their users. Presence is a human reaction to immersion, which is a more objective variable that depends on the devices and the software used for the simulation [14]. While immersion is a technology factor, presence is a subjective experience. Different individuals may experience different levels of presence in the same virtual reality because people have varying susceptibility to feeling present in a virtual environment. Immersive tendency and visual ability are relating factors to this individual variability [15].

The first step in the process of experiencing presence is that the technology immerses the users' senses and body into the virtual reality. Then different cognitive processes foster the creation of the mental model of the VR and the immersed body. Then, finally, the user experiences the sense of presence, the feeling of being inside the virtual environment [16]. Different factors contribute to the sense of presence such as control, realism, distraction and sensory input [17]. For experiencing the sense of presence, it is important for the user to have control over the environment. Thus, the controller device can play a role too. A naturally mapped interface requires less thinking about controlling, thus the user more 
effortlessly feel "inside" the environment. The controller naturalness is also a subjective variable, as the users have different experiences with a different controller. The perceived naturalness of the controller could predict the spatial presence [18].

\section{Virtual Reality in Education}

In the theory of multimedia learning, Mayer emphasizes the importance of the limited cognitive capacity of humans. This means that only a limited amount of information can be processed by the visual and auditory channels. According to this theory, learners can engage in three kinds of cognitive processing (or cognitive load) during learning: extraneous, essential and generative [19]. Cognitive load is the relative demand imposed by a particular task, in terms of mental resources required [20]. Extraneous cognitive processing refers to the cognitive processes which do not serve an instructional goal. For example, a sluggish interaction with the virtual environment because of poor design or lack of experience. Essential processing is the selection of relevant information, and generative cognitive processing refers to the organization of these materials. This latter allows a deeper understanding of the learning material [19].

It is widely accepted that virtual reality can enrich the students' educational experience. Furthermore, VR can enhance the learning outcome of students. The sense of presence positively influences the students' interest and motivation to interact with the simulation [21, 22]. The learning outcome is affected by the presence: they have a positive relationship in just a ten minute session [23]. Earlier research suggested that there is a direct relationship between presence and the learning outcome, based on their structural equation modeling approach [24]. A recent research [22] also investigated the process of learning in VR with the help of structural equation modeling. Their results did not support the previous results with the direct relationship. They found two general paths: an affective and a cognitive one by which desktop VR led to increase the learning outcome after a VR lesson. The affective path led through VR features, presence, intrinsic motivation and self-efficacy; the cognitive path went through VR features, usability, cognitive benefits, and self-efficacy [22]. In this model, the sense of presence arises from VR features such as the degree of realism and control factors. This initial relationship, that higher fidelity causes more presence was similar to earlier research, but there the higher fidelity also caused less learning presumably due to the irrelevant sensory information [25]. However, in this new model, the role of presence in learning depends on other factors such as intrinsic motivation and self-efficacy [22]. To sum up, a higher sense of presence is related to better learning outcomes, but other factors such as intrinsic motivation and self-efficacy mediate this relationship. 


\section{Research Objectives}

Virtual reality is part of the digital transformation of education, and it is already started to spread in different educational institutions. The Széchenyi István University is promoting the use of virtual education and the VR Learning Center of the university plays a role in developing basic methodologies for VR-based education. The used VR platform is the MaxWhere [26] virtual reality. This desktop VR enables the teachers and students to create and share 3D learning spaces, where any web content, document, video or image can be displayed. The spatial arrangement helps the student to understand the structure of the learning material [27]. Moreover, there are also virtual laboratories for engineering students $[8,9,10]$. The MaxWhere VR was already in the focus of numerous scientific research $[27,28,29,30]$, but none of them measured the sense of presence, however, it relates to the learning outcome.

The aim of the current study is to investigate the sense of presence in MaxWhere virtual reality. This research also investigated whether there is a difference between novice and more experienced users in experiencing presence. As the focus was on one specific VR we did not compare different navigational devices, but the navigational experience of users.

\section{Methods}

\subsection{Subjects}

Thirty-one (6 female and 25 male) individuals' data were analyzed form the original thirty-six participants. Five people were excluded due to data loss or other problems during the experimental procedure. The mean age was 20.5 years (SD: 3.4).

\subsection{Measures}

\subsubsection{Presence}

The sense of presence was measured by the Igroup Presence Questionnaire (IPQ) [16]. This 14-item questionnaire has three subscales: spatial presence, involvement, and experienced realism. Spatial presence measures the sense of being physically present in the simulated environment, involvement assesses the awareness devoted to the virtual reality. The experienced realism factor shows the 
subjective experience of realism in virtual reality. IPQ contains a general item, which measures the general presence: In the computer-generated world, I had a sense of 'being there' [16]. Measures were made on seven-point scales, with lower scores indicating disagreement. All subscales had an acceptable level $(\alpha>0.7)$ of reliability in the present study.

\subsubsection{Navigational Experience}

For measuring the participants navigational experience in the virtual reality, we created a five-item scale: I moved confidently in the space", "I felt that I was controlling my movements in space", "I had difficulty navigating to the place where I wanted to go" (reverse-scored item), "Navigation in virtual space was automatic for me", "I felt natural moving in the virtual space". Participants had to indicate their agreement on a ten-point Likert-scale. The Cronbach's $\alpha$ of the scale was 0.883 , therefore this scale can be considered as reliable.

\subsection{Procedure}

In the experiment, the MaxWhere [26] desktop virtual reality was used. After giving consent to take part in the research, users navigated in the virtual reality and solved different tasks for about 15 minutes. After this navigating session they filled the Igroup Presence Questionnaire, they rated their navigational experience and answered basic demographic questions. They also had to indicate their prior MaxWhere knowledge.

\section{Results}

Means and standard deviations for the IPQ subscales and the navigational experience scale are presented in Table 1.

Table 1

Means and standard deviations of the measured variables

\begin{tabular}{|c||c|c||c|c|c|c|}
\hline \multicolumn{1}{|c||}{} & \multicolumn{2}{c||}{ All participants } & \multicolumn{2}{c|}{ Novice } & \multicolumn{2}{c|}{$\begin{array}{c}\text { More } \\
\text { experienced }\end{array}$} \\
\cline { 2 - 7 } & Mean & SD & Mean & SD & Mean & SD \\
\hline \hline Navigational experience & 7.04 & 2.19 & 6.64 & 2.44 & 7.67 & 1.53 \\
\hline IPQ - General presence & 2.7 & 1.7 & 2.4 & 1.5 & 3.2 & 2.0 \\
\hline IPQ - Spatial presence & 3.06 & 1.27 & 2.67 & 1.06 & 3.67 & 1.34 \\
\hline IPQ - Involvement & 2.6 & 1.27 & 2.45 & 1.3 & 2.83 & 1.2 \\
\hline IPQ - Experienced realism & 1.82 & 1.04 & 1.5 & 0.9 & 2.32 & 1.04 \\
\hline
\end{tabular}




\subsection{Navigational Experience Correlates with the Presence}

The Pearson correlation showed a statistically significant positive correlation between the individual navigational experience score and the spatial presence scores $\mathrm{r}(29)=0.497, \mathrm{p}=0.004$. To be precise, the more automatic navigation correlated with a higher sense of spatial presence.

\subsection{Novice and Experienced Users}

Subjects were divided into two groups based on their prior experience with this virtual reality. Those, who used already this virtual reality at least one hour before the experiment, were the experienced users and those who had no or up to onehour experience were considered as novice users. Twelve participants were in the experienced group and nineteen in the novice group. The mean scores and standard deviations of each variable for each group are presented in Table 1. The mean scores of IPQ subscales are summarized in a boxplot in Fig. 1.

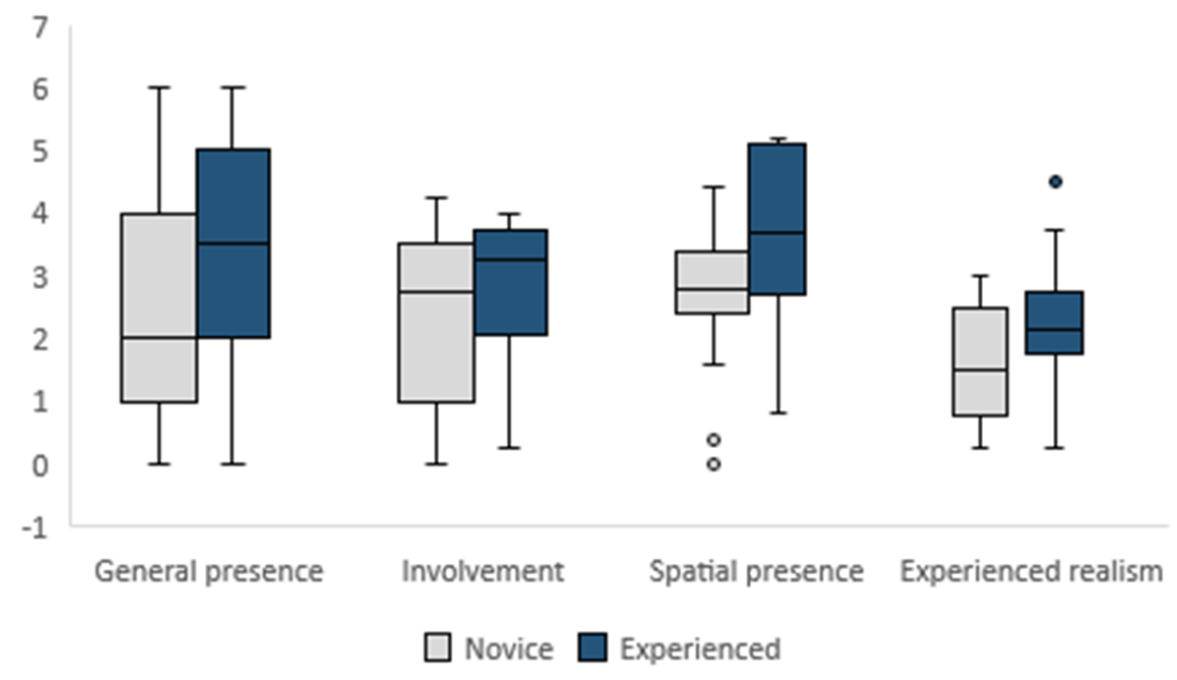

Figure 1

Scores on IPQ subscales among novice and more experienced participants

First of all, we tested whether the navigational abilities of the participants are roughly equal in the two groups. For this, we used an independent sample t-test. The test showed that no significant difference $(t(29)=-1.26, \mathrm{p}=0.217)$ was found for the navigational experience scores of the novice (6.64) and the experienced (7.67) group. Thus, the differences in sense of presence between the two groups are not related to differences in their navigational ability. 
The independent sample t-test showed no significant difference between the novice (2.4) and the experienced (3.2) group for general presence $(\mathrm{t}(29)=-1.37, \mathrm{p}$ $=0.182)$. The Mann Whitney $U$ test $(U=92.5, p=0.392)$ showed no significant difference for the involvement scores between the two groups (novice: 2.447, experienced: 2.833). The level of general presence was similar in the two groups and also the involvement, which is the attention devoted to the environment.

The results showed that spatial presence $(\mathrm{t}(29)=-2.21, \mathrm{p}=0.035)$ and experienced realism $(\mathrm{t}(29)=-2.23, \mathrm{p}=0.034)$ were significantly higher in the experienced group (SP: 3.67; REAL: 2.32) than in the novice group (SP: 2.67; REAL: 1.5). Hence the novice users experienced less spatial presence than those who had at least one hour of prior experience with the software. Furthermore, they rated the virtual environment less realistic than the more experienced participants.

\section{Discussion}

The aim of this study was to investigate the sense of presence in MaxWhere virtual reality: its relationship with the subjective navigational experience and the differences between novice and more experienced users. The results showed positive correlation between the navigational experience and spatial presence scores. Furthermore, the more experienced users gave higher ratings on the spatial presence and experienced realism subscales, but the general sense of presence and involvement did not differ between these two groups.

The positive correlation between the subjective navigational experience and the spatial presence means that those who rated the navigational experience more automatic and natural, experienced a higher sense of spatial presence in the virtual environment. This easier and more automatic navigation can also relate to the controller naturalness. In an earlier study, the controller naturalness positively predicted the spatial presence [18]. A naturally mapped interface requires less thinking about controlling the virtual reality and allows users to feel in the virtual environment more effortlessly. In the present study, only one type of controller was used, but the perceived navigational experience closely relates to this construct.

In this study, the level of experience with the software was a key factor. Based on this, the participants were categorized as novice and more experienced users. The latter ones had at least one-hour prior experience with the MaxWhere software. The scores on the involvement subscale did not differ between the two groups: they devoted roughly the same amount of attention to the virtual reality and the experimental task. Thus, external factors did not influence the difference between these groups, neither group was disrupted from the VR more frequently. Also, the general sense of presence, the sense of "being inside" the virtual environment did 
not differ between the groups. Thus, the overall sense of presence was not related to prior experience with the software.

The spatial presence score, which measures the sense of being physically present in the VR, was higher among the more experienced users. In early VR studies, the most common difference between novice and experienced users was the navigation ability [36], but in this study, we found no significant difference in the navigational experience of users with different levels of experience. But they could have more cognitive resources to the details of the VR as they could use the software more automatically. For example, the more experienced users could have used the gesture-based activation mode of the smartboard, instead of the clicking on the corresponding button. But this variable was not measured in this study. For more information on the gesture-based method and spatial navigation in this virtual reality, the study of Sudár and Csapó (2019) [29] is recommended.

The other difference was in the score of experienced realism, which was also higher among experienced users. Presumably, they could use their more cognitive resources to observe the details of the VR. Another possible explanation relates to the fact that prior rating of the same virtual reality sensitizes observers to its different features, which could result in different presence scores [32]. Namely, the more experienced users can have more concrete expectations about the VR. Besides, the novice participants could genuinely compare the virtual experience to the reality, which also can cause the lower ratings on the experienced realism subscale. The experienced realism scores were the lowest for both groups among the IPQ factors. This could be since the MaxWhere virtual reality was not intended to replicate a real place, but to create a virtual space for learning and working. The high representational fidelity could evoke a stronger sense of presence but less learning, presumably due to the irrelevant sensory information [25].

The overall pattern of these results shows that the more experienced participants gave similar or higher ratings of different presence factors. Therefore, this VR is not just a cool technique to enrich the students' educational experience, but repeated use can extend the sense of presence. Given that presence can be a key factor in learning outcomes [22, 23, 24], it could be a way to increase the students' motivation of student and self-efficacy [22] which leads to better learning outcomes. But of course, presence is not the only fundamental variable in a virtual learning environment the educational materials and resources also have a high impact on learning outcomes [33].

\section{Conclusions}

This study examined the sense of presence, in MaxWhere virtual reality. The results showed that more automatic navigation positively relates to spatial presence. A significant difference was found in the spatial presence and experienced realism: the more experienced users gave higher ratings on both subscales. But both the involvement and the general sense of presence were 
similar, which is advantageous in education, as the presence is positively related to the learning outcome.

\section{Acknowledgement}

This work was supported by the ÚNKP-19-3-I-SZE-1 New National Excellence Program of the Ministry for Innovation and Technology.

\section{References}

[1] P. Baranyi and A. Csapo: Definition and synergies of cognitive infocommunications, Acta Polytechnica Hungarica, Vol. 9, 2012, pp. 67-83

[2] P. Baranyi, A. Csapo and G. Sallai: Cognitive Infocommunications (CogInfoCom), Springer, 2015, p. 219

[3] M. Dergham and A. Gilányi: Application of Virtual Reality in Kinematics Education," in Proceedings of the $10^{\text {th }}$ IEEE International Conference on Cognitive Infocommunications: CogInfoCom 2019, 2019

[4] M. Al-Adawi and M. Luimula: Virtual reality in Fire Safety - Electric Cabin Fire Simulation," in Proceedings of the $10^{\text {th }}$ IEEE International Conference on Cognitive Infocommunications: CogInfoCom 2019, 2019

[5] E. Markopoulos, J. Lauronen, M. Luimula, P. Lehto and S. Laukkanen: Maritime Safety Education with VR Technology (MarSEVR), Proceedings of the $10^{\text {th }}$ IEEE International Conference on Cognitive Infocommunications: CogInfoCom 2019, 2019

[6] A. Gilányi, A. Rácz, A. M. Bólya and K. Chmielewska: Early History of Hungarian Ballet in Virtual Reality, Proceedings of the $10^{\text {th }}$ IEEE International Conference on Cognitive Infocommunications: CogInfoCom 2019,2019

[7] F. Bellalouna: Virtual-Reality-based Approach for Cognitive DesignReview and FMEA in the Industrial and Manufacturing Engineering, in Proceedings of the $10^{\text {th }}$ IEEE International Conference on Cognitive Infocommunications: CogInfoCom 2019, 2019

[8] T. Budai és M. Kuczmann: A multi-purpose virtual laboratory with interactive knowledge integration, Proceedings of the $10^{\text {th }}$ IEEE International Conference on Cognitive Infocommunications: CogInfoCom 2019,2019

[9] Z. Kvasznicza: Teaching electrical machines in a 3D virtual space, $8^{\text {th }}$ IEEE International Conference on Cognitive Infocommunications, Debrecen, 2017, pp. 385-388

[10] M. Kuczmann and P. Baranyi: State Space Model Based control in Virtual Laboratory, Proceedings of the $10^{\text {th }}$ IEEE International Conference on Cognitive Infocommunications: CogInfoCom 2019, 2019 
[11] G. Bujdosó, K. Boros, C. M. Novac and O. C. Novac: Developing cognitive processes as a major goal in designing e-health information provider VR environment in information science education, Proceedings of the $10^{\text {th }}$ IEEE International Conference on Cognitive Infocommunications: CogInfoCom 2019, 2019

[12] Z. Merchant, E. T. Goetz, L. Cifuentes, W. Keeney-Kennicutt and T. J. Davis: Effectiveness of virtual reality-based instruction on students' learning outcomes in K-12 and higher education: A meta-analysis, Computers \& Education, Vol. 70, 2014, pp. 29-40

[13] M. Slater and S. Wilbur: A framework for immersive virtual environments (FIVE): Speculations on the role of presence in virtual environments," Presence: Teleoperators \& Virtual Environments, Vol. 6, 1997, pp. 603-616

[14] M. Slater: A note on presence terminology, Presence Connect, Vol. 3, 2003, pp. 1-5

[15] Y. Ling, H. T. Nefs, W.-P. Brinkman, C. Qu and I. Heynderickx: The relationship between individual characteristics and experienced presence, Computers in Human Behavior, Vol. 29, 2013, pp. 1519-153

[16] T. Schubert, F. Friedmann and H. Regenbrecht: The experience of presence: Factor analytic insights, Presence: Teleoperators \& Virtual Environments, Vol. 10, 2001, pp. 266-281

[17] B. G. Witmer and M. J. Singer: Measuring Presence in Virtual Environments: A Presence Questionnaire, Presence: Teleoperators and Virtual Environments, Vol. 7, 1998, pp. 225-240

[18] P. Skalski, R. Tamborini, A. Shelton, M. Buncher and P. Lindmark: Mapping the road to fun: Natural video game controllers, presence, and game enjoyment, New Media \& Society, Vol. 13, 2011, pp. 224-242

[19] R. E. Mayer: The Science of Learning: Determining How Multimedia Learning Works, Multimedia Learning, $2^{\text {nd }}$ ed., Cambridge University Press, 2009, pp. 57-84

[20] American Psychological Association (APA): Cognitive load definition, [Online] Available: https://dictionary.apa.org/cognitive-load [Accessed 15. 11. 2019.]

[21] G. Makransky and L. Lilleholt: A structural equation modeling investigation of the emotional value of immersive virtual reality in education, Educational Technology Research and Development, Vol. 66, 2018, pp. 1141-1164

[22] G. Makransky and G. B. Petersen: Investigating the process of learning with desktop virtual reality: A structural equation modeling approach," Computers \& Education, Vol. 134, 2019, pp. 15-30 
[23] M. N. Selzer, N. F. Gazcon and M. L. Larrea: Effects of virtual presence and learning outcome using low-end virtual reality systems, Displays, Vol. 59, 2019, pp. 9-15

[24] E. A.-L. Lee, K. W. Wong and C. C. Fung: How does desktop virtual reality enhance learning outcomes? A structural equation modeling approach, Computers \& Education, Vol. 55, 2010, pp. 1424-1442

[25] G. Makransky, T. S. Terkildsen and R. E. Mayer: Adding immersive virtual reality to a science lab simulation causes more presence but less learning," Learning and Instruction, Vol. 60, 2019, pp. 225-236

[26] "MaxWhere Store - VR workspaces": [Online] Available: https://www.maxwhere.com/ [Accessed 20. 11. 2019.]

[27] Á. B. Csapó, I. Horváth, P. Galambos and P. Baranyi: VR as a Medium of Communication: from Memory Palaces to Comprehensive Memory Management, 2018 IEEE $9^{\text {th }}$ International Conference on Cognitive Infocommunications (CogInfoCom), 2018

[28] A. Gilányi, G. Bujdosó and M. Bálint: Presentation of a medieval church in MaxWhere, $20178^{\text {th }}$ IEEE International Conference on Cognitive Infocommunications (CogInfoCom), 2017

[29] A. Sudár és Á. B. Csapó: Interaction Patterns of Spatial Navigation in VR Workspaces, Proceedings of the $10^{\text {th }}$ IEEE International Conference on Cognitive Infocommunications: CogInfoCom 2019, 2019

[30] I. Horváth: Evolution of teaching roles and tasks in VR / AR-based education, $9^{\text {th }}$ IEEE International Conference on Cognitive Infocommunications, Budapest, 2018, pp. 355-360

[31] C. Greenhalgh and S. Benford: MASSIVE: a collaborative virtual environment for teleconferencing, ACM Transactions on Computer-Human Interaction (TOCHI), Vol. 2, 1995, pp. 239-261

[32] J. Freeman, S. E. Avons, D. E. Pearson and W. A. IJsselsteijn: Effects of sensory information and prior experience on direct subjective ratings of presence, Presence: Teleoperators \& Virtual Environments, Vol. 8, 1999, pp. $1-13$

[33] I. Horváth: How to develop excellent educational content for $3 \mathrm{D}$ VR, Proceedings of the $10^{\text {th }}$ IEEE International Conference on Cognitive Infocommunications: CogInfoCom 2019, 2019 